\title{
Dialysis Patients and Cardiovascular Problems: Can Technology Help Solve the Complex Equation?
}

\author{
Claudio Ronco ${ }^{a}$ Sudhi Bowry ${ }^{b}$ Ciro Tetta $^{b}$ \\ ${ }^{a}$ Department of Nephrology, St. Bortolo Hospital, Vicenza, Italy; ${ }^{b}$ Fresenius Medical Care GmbH, \\ Bad Homburg, Germany
}

\author{
Key Words \\ Cardiovascular complications · Online \\ hemodiafiltration - Dialysis machine
}

\begin{abstract}
Patients with end-stage kidney disease undergoing chronic hemodialysis (HD) present higher mortality rates compared with the general population. Once patients are on HD, the risk of cardiovascular death is approximately 30 times higher than in the general population and remains 10-20 times higher after stratification for age, gender, and the presence of diabetes. About half the deaths of patients on dialysis are attributed to cardiovascular causes including coronary heart disease, cerebrovascular disease, peripheral vascular disease, and heart failure. The cardiovascular burden of the HD patient arises from three different sources: risks inherent to the patient and the uremic syndrome, traditional risk factors, and risk factors related to the dialysis therapy. Based on these considerations and the fact that several aspects of the dialysis procedure can either add to the cardiovascular burden or modify the existing burden, new technologies should be directed towards the approach of a potential 'cardioprotective dialysis therapy'; such an approach may be facilitated by the application of new techniques and advanced dialysis machines. Created to make dialysis easy and safe, new machines feature sev-
\end{abstract}

eral options that make patient monitoring and online hemodiafiltration therapy routine procedures. These and other features will possibly make dialysis better tolerated and more efficient in protecting patients from undesirable or potentially fatal cardiovascular events.

Copyright (C) 2006 S. Karger AG, Basel

\section{Introduction}

Complications associated with hemodialysis (HD) mostly involve the cardiovascular system. Patients present higher mortality rates compared with the general population, which is attributed to cardiovascular disorders including heart failure, coronary heart disease, and peripheral vascular disease [1-5]. Today, the challenge of new technologies in HD is related to the capacity of completely, or at least partly, overcoming the severe metabolic and clinical disorders that lead to major cardiovascular events [6-18]. New technology in dialysis cannot modify the factors intrinsic to the patient such as diabetes or genetic abnormalities but it should at least consider the possibility of favorably modifying some of the other risk factors implicated in the genesis of cardiovascular disorders such as anemia, chronic inflammation, oxidative stress, and advanced glycation end products (AGEs). Lifestyle-associated risk factors such as smoking, obesity and inactivity should be considered separately.

\section{KARGER}

Fax +41613061234 E-Mail karger@karger.ch www.karger.com 


\section{Traditional and Non-Traditional Cardiovascular Risk Factors}

The uremic state per se contributes to the bulk of the risk of cardiovascular disease in HD patients, and in this setting, inflammation plays a crucial role. Furthermore, most HD patients suffer from one or a number of comorbid conditions such as hypertension and diabetes that exacerbate uremia and vice versa. The cardiovascular burden carried by dialysis patients is multi-factorial and can thus be increased when uremia-related and traditional risk factors (affecting the general population) are combined. A third source of contribution to the overall cardiovascular burden could be the inadvertent and adverse influence of certain features related to the dialysis procedure.

\section{Oxidant Stress, Inflammation and Accelerated Atherosclerosis}

End-stage renal disease (ESRD) patients suffer from a state of chronic inflammation leading to cardiovascular complications, progressive malnutrition, and death [1920]. Inflammation is subclinical, and chronic disorders of the cytokine system or acute phase proteins may be observed as the sole evidence of a proinflammatory disorder $[21,22]$.

There are several reasons why HD patients are associated with chronic inflammation. The condition of uremia per se is characterized by a series of metabolic disturbances that produce an imbalance between immunostimulation and immunodepression. There is a disequilibrium between the production of reactive oxygen species and the antioxidant defense of the organism [23]. The HD membrane together with several other components of the dialysis may lead to a condition of subclinical, progressive inflammation. However, cardiovascular disease is often already present in asymptomatic patients with renal failure and on conservative treatment [24]. This may also be exacerbated by other comorbid states including infections, periodontal disease, and atherosclerosis [25-28].

All these factors seem to combine their action to produce long-term clinical derangements. In particular, the production of proinflammatory cytokines as a response to a specific stimulus increases the level of acute phase reactants - C-reactive protein (CRP), fibrinogen, serum amyloid A, transferrin - triggering a cascade of events including endothelial dysfunction, accelerated atherogenesis, and cardiovascular disease [25-28]. Mortality, morbidity and hospitalization are positively correlated with the serum acute phase proteins such as CRP, serum amyloid A, and soluble adhesion molecules, as well as with the cytokines that regulate them (IL-6), in HD patients as well as in the general population [21-27].

Leptin and $\beta_{2}$-microgobulin are molecules in the middle weight range considered important factors in accelerating the cardiovascular damage in ESRD patients. Dyslipidemia, bioincompatibility of dialysis membranes, oxidative stress and anemia are other important risk factors involved in the aggravation of cardiovascular disorders, and again, high-molecular weight erythropoiesis inhibitors have been demonstrated to play an important role in this disorder.

\section{The Additional Burden of Potentially Contaminated Dialysate}

Contaminated dialysis fluid, or water quality, are further important issues, together with the silent chronic inflammation and the formation of AGEs. There are inflammatory disorders which are thought to contribute to the pathogenesis of atherosclerosis in HD patients. AGEs act synergistically with endotoxins, and the cytokine-inducing effect of AGEs plus endotoxin is more potent than the effect of either alone. In conclusion, ESRD patients are at risk for cardiovascular disease, and early atherosclerotic lesions seem to contribute to negative outcomes. What can we do to correct or prevent such conditions and possibly improve the outcome? Is modern technology able to respond in a positive way to this challenge?

\section{The Challenge of New Technologies and Biomaterials}

The application of new technologies involves the use of new biomaterials designed to ameliorate dialyzer and membrane performance, the application of these advanced dialyzers in therapeutic modalities that attempt to exploit the maximal capacity of blood purification procedures involving different mechanisms including convection, and the utilization of dialysis machines whose functions are well integrated in the concepts of safety, quality of therapy, performance, easy monitoring, and having a friendly user interface.

It is well known that modern high-flux dialyzers can efficiently remove different-sized uremic retention solutes [31, 32]. Wanner et al. [33], in a randomized cross- 
over study (36 patients), showed the influence of dialyzer flux and membrane material on the three cardiovascular disease risk factors. Patients showed improved lipid and apolipoprotein profiles after 6 weeks of high-flux treatment. In particular, levels of oxidized low-density lipoprotein were significantly reduced when treated with the new Helixone polysulfone membrane in comparison with the cellulose triacetate membrane. The essential features of contemporary dialysis membranes have recently been improved through the application of novel nanotechnology principles during the process of membrane spinning, especially involving the controlled precipitation step that defines the fine structure of the hollow-fiber membrane wall [34-36].

There is evidence for beneficial effects of high-flux dialysis (compared with low-flux dialysis) in controlling renal anemia and reducing the cost of the therapy, an effect probably achieved by the efficient removal of middle- and high-molecular weight erythropoiesis inhibitors [37]. A number of papers have shown that endotoxin elimination from dialysis fluids necessitates the usage of efficient water treatment systems as well as dialyzer membranes having a high endotoxin retention capacity. Modern dialysis machines, in conjunction with advanced water treatment systems, facilitate the achievement of ultrapure dialysate through multiple steps of filtration occurring in specific filters placed in the dialysate circuit of the machine [38].

Two recent publications have highlighted the membrane material-dependent retention of endotoxins from contaminated dialysate. Weber et al. [39] showed that polysulfone-based membranes had a significantly higher endotoxin retention compared with two polyarylethersulfone-based membranes. Likewise, Schindler et al. [40] demonstrated differences in the permeability of high-flux dialyzer membranes for bacterial pyrogens, concluding that dialyzers that leak cytokine-inducing substances should not be used unless the dialysate has passed through an ultrafilter.

An association between ultrapure dialysate and iron utilization and erythropoietin response in chronic HD patients has recently been published [41, 42]. Endotoxin reduction by cold filtration led to reduced CRP plasma levels, reduced EPO dose, and improved iron utilization.

Today, based on these studies and observations, one can approach dialysis therapy with the attempt not only to reduce the level of uremic intoxication, but also to implement a series of potentially cardioprotective measures and treatment modalities.

Cardiovascular Problems in Dialysis Patients

\section{From Ultrapure Dialysate to Online Hemodiafiltration}

Treatment modalities that involve convection, rather than diffusion, as the predominant mechanism of uremic toxin removal are increasingly being acknowledged as more relevant in that, like the natural kidney, a broader spectrum of uremic retention solutes are removed. Further, it is now becoming apparent that significant additional advantages can be attributed to therapy modalities, such as hemodiafiltration (HDF), which more efficiently eliminate middle molecules $[43,44]$ and point towards improving patient outcomes. However, the increased removal of middle molecules might be associated with a high leakage of essential substances like albumin from the patient's blood, thereby perhaps compromising the nutritional status of the patient. For this reason, new membranes with nanocontrolled characteristics are increasingly used to achieve the maximal benefits from a large removal of middle molecules but minimizing the loss of important nutrients such as albumin $[45,46]$. These new membranes take the maximal advantage of convection, and therefore, high volume exchanges are used to maximally exploit the capacity of the membrane. For this reason, online hemofiltration is the therapy of choice in providing efficient removal of a wide spectrum of molecules.

Another issue of concern in contemporary dialysis therapy is how to cope with severe fluctuations of physiological processes during a single dialysis session, as well as in the intradialytic interval. Dialysis profiling is now being recognized as highly useful in providing quality assurance through monitoring of the therapy during each and every dialysis session. Further, it also reduces the incidence and occurrence of severe unphysiological events, thereby ensuring safety to the dialysis care team as well as the patient, and possibly provides a favorable influence on patient outcomes [47].

\section{Cardioprotective Hemodialyis: The Role for a ‘New’ Dialysis Machine}

The Hemodialysis study showed a $20 \%$ reduction in cardiac death and a 13\% decrease in the composite of first cardiac hospitalization or cardiac death as a result of high-flux dialysis compared with low-flux dialysis [48]. Improving biocompatibility and solute removal by convection and reducing the burden of HD on hypo-/hypertension, salt and water overload and left ventricular hy- 


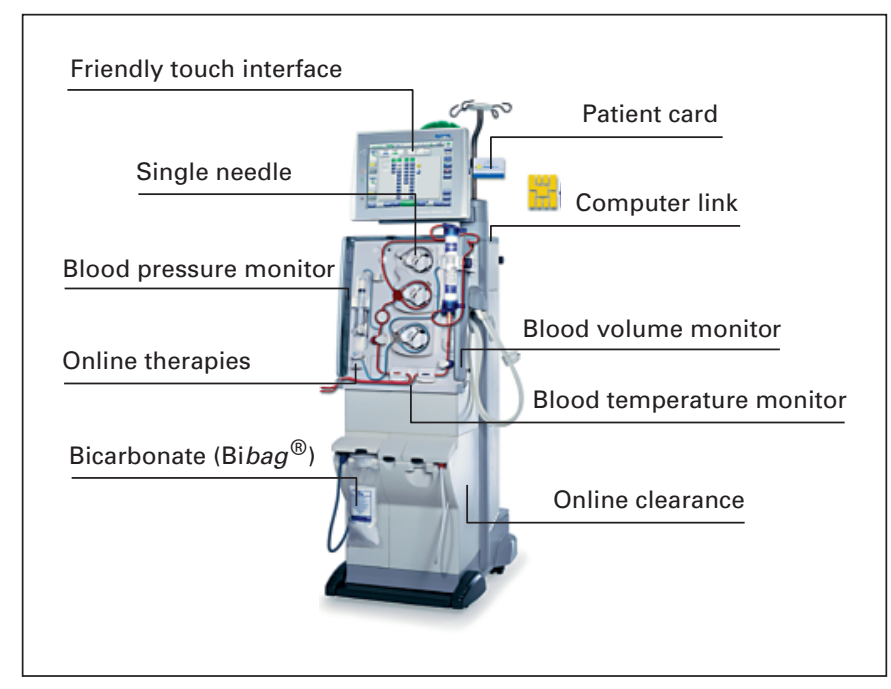

Fig. 1. Example of a newly developed dialysis machine (5008, Fresenius Medical Care). Several features are part of the machine and can be used in the clinical routine. The machine looks compact and includes a user-friendly touch screen with a simple and logic instruction and information layout. It carries the option of a single needle and it is designed to perform online therapies as a routine. Bicarbonate in powder is used as alkaline concentrate while a series of online sensors are available including blood pressure, blood volume, and blood temperature monitors. Online clearance and urea kinetics are part of the machine and based on ionic dialysate with a double-step sodium concentration and conductivity changes. The machine is designed to make data collection and recording easy. Patient data can be stored in a personalized card interacting with the machine.

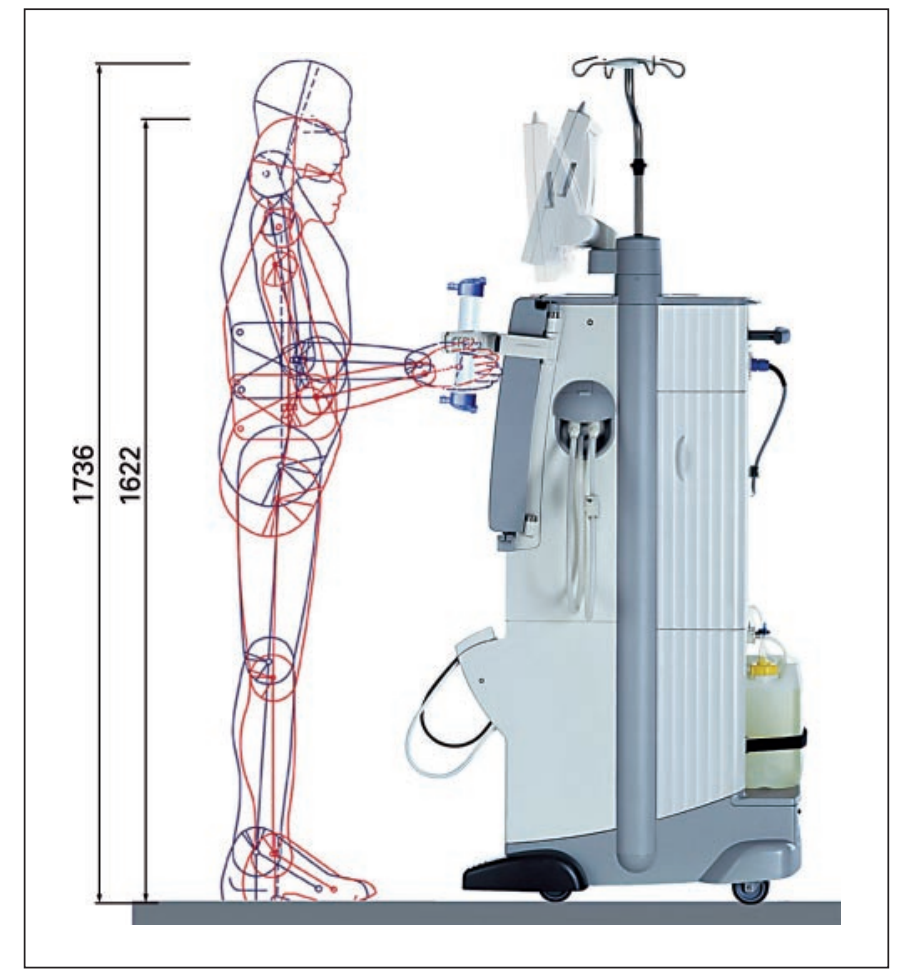

Fig. 3. The friendly special configuration of the machine and the user interface.

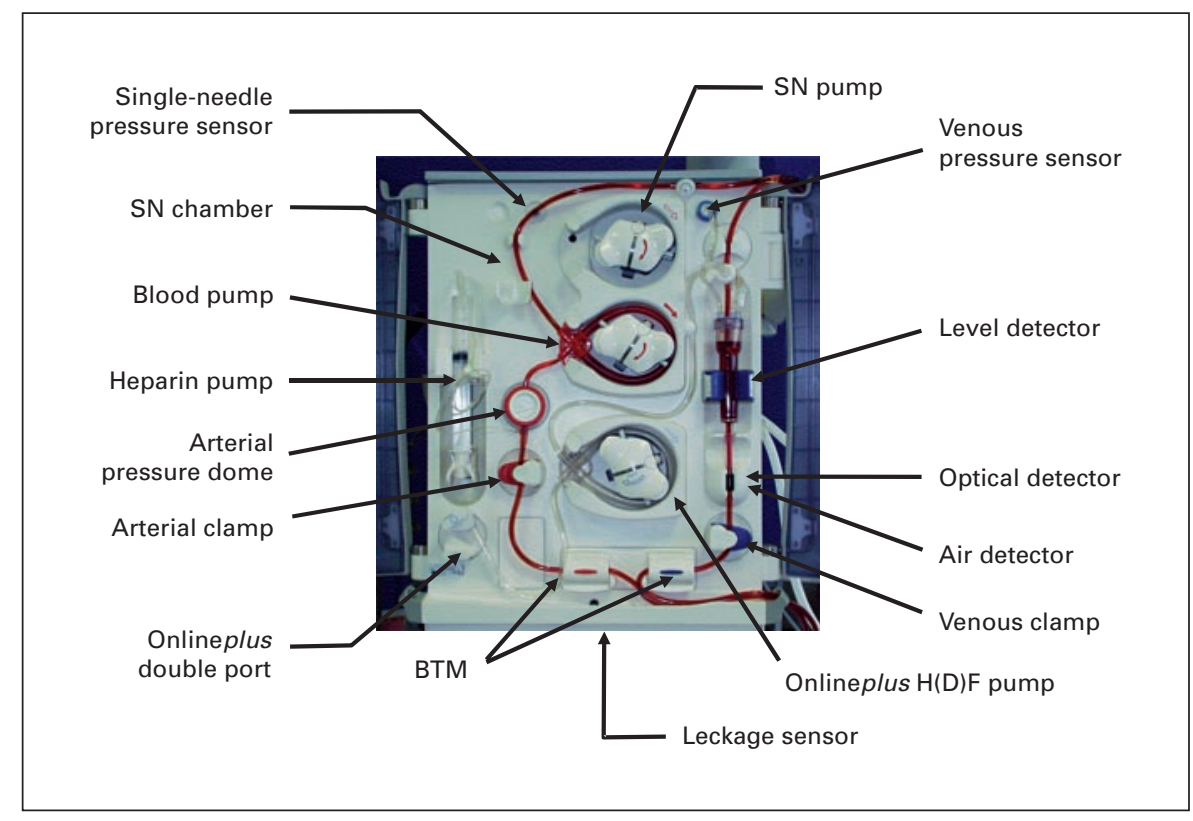

Fig. 2. The blood circuit in the 5008 machine. Besides all typical safety features in the blood circuit, the machine is designed for online therapies providing multiple-step filtration of fluid, guaranteeing the delivery of ultrapure dialysate. For this purpose, polisulfone filters are placed on the back side of the machine and integrated in the dialysate circuit. $\mathrm{SN}=$ Needle sensor; $\mathrm{BTM}=$ blood temperature monitor. 
pertrophy are the cornerstones of "cardioprotective dialysis'. Thus, the creation of a new dialysis machine must take into account all those features that might affect the final outcome, or at least, contribute towards the concept of performing 'cardioprotective dialysis' (fig. 1) Treatment-related variations relate to changes in the concentration of uremic retention solutes (e.g., urea) as well as to the volume status/dry weight of the patient: these variations are monitored and accounted for with specific tools integrated in the dialysis machine. The online clearance monitoring relies on the measurement of the ionic strength of the dialysate and is then correlated to urea clearance; this is required for the estimation of the dose of dialysis $(\mathrm{Kt} / \mathrm{V})$, an index that is associated with patient outcomes. The online clearance monitoring also measures the plasma $\mathrm{Na}^{+}$concentration of the patient, thus enabling the attending nephrologist to individualize the prescription with respect to the dialysate $\mathrm{Na}^{+}$concentration. Blood volume measurement contributes to monitor the circulating volume, to maintain normovolemia, and to reach dry weight. In general, the uremic population is confronted with vascular impairment attributed to arterial stiffness, making it harder to regulate the fluid status/regulation. This aspect of vascular dysfunction is further aggravated by dialysis therapies when large unphysiological changes in hemodynamic responses occur in response to rapid fluid removal by ultrafiltration; attaining normovolemia in a controlled, gradual manner would clearly be less damaging to the patient $[49,50]$. Online blood volume monitoring helps regulate the fluid removal during the treatment: ideally, the ultrafiltration rate is adjusted automatically, preferably according to the patient's plasma refilling rate. Clinical studies have demonstrated the usefulness of blood volume monitoring in reducing hypotensive episodes [51]. The maintenance of an adequate vascular tone and sympathetic response has been correlated with the thermal energy balance during dialysis. The online blood temperature monitor permits the regulation and stabilization of intradialytic body temperature, thereby achieving cardiovascular stability; its application has been shown to have a considerable positive effect on the intradialytic vascular stability [52].

\section{From Expensive Technical Gadgets to Useful Tools for Routine Monitoring}

Today, online HDF is already a widespread and wellaccepted treatment modality. It is also the dialysis modality for which more technology has been produced and inventiveness articulated [53]. At the time of writing, data from 4,504 patients followed from 1998 to 2001 in five European countries (in the course of the Dialysis Outcomes and Practice Patterns Study) are being reanalyzed. Preliminary results show that after adjustment of patient demographics and comorbid conditions, patients receiving online HDF appear to have a significantly reduced risk of mortality. In an initial presentation of these data, a $23 \%$ reduction in mortality was described [54]. However, this reduction was smaller than in reality, since data from online HDF (20-24 liters), HDF with 10-20 liters and HDF with 6-10 liters were all computed together, leading to no significant reduction. A reduced risk of mortality has also been shown preliminarly in the Euclid ${ }^{\circledR}$ database based on data from the Fresenius Medical Care Clinics in Europe [55-56]. Apart from other forms of HDF (acetate-free biofiltration, push-pull, mid-dilution, paired filtration dialysis), online HDF has constantly increased its popularity, possibly based on the following facts. Firstly, the unlimited amount of fluid which can be produced online under proven and experience-based safety protocols will further encourage the application of increased convection [57]. New perspectives in the use of pre- and postinfusion, controlled by the transmembrane pressure ultrafiltration feedback, may enable a more complete exploitation of the convective mechanism [58]. Secondly, the 5008 machine, the most recent dialysis machine customized specifically for online HDF, will help improve the hemodynamic instability and fulfill the new concept of online HDF as a cardioprotective modality. Online HDF thus appears to set new standards in patients' quality care and a better way to exploit present and future technology. The repercussion will contribute to an ever wider acceptance not only of online HDF but in reducing the negative effects of contaminated dialysate, still very prevalent today in most dialysis units, used in conventional HD. As has been the case in the past also for online HDF, the advantages will counterbalance drawbacks [59]. As the Agence nationale d'accréditation et d'évaluation en santé has stated '... processes for establishing and maintaining the quality of their water treatment should be installed in order to insure that monitoring and prevention be put into practice' [60]. This implies the combined effort of nephrologists, pharmacists, hospital bioengineers, and industry in a team work attitude. Public agencies will have the duty to check and accredit validated protocols in each center. This is even more important in the light of a decreased risk of mortality being associated with high convective online HDF. This is exactly how HD has evolved since its early days and how it 
can be further developed. Thirdly, full automation of the dialysis machine will open the practical adoption of daily online HDF of which the clinical benefits have been already reported. In conclusion, the new step in technology provided by the 5008 machine is not simply the introduc- tion of new series of features provided by the machine, but rather the possibility of using all these new features as a routine for an improved efficiency and tolerance for the patient [61].

\section{References}

1 Go AS, Chertow GM, Fan D, et al: Chronic kidney disease and the risks of death, cardiovascular events, and hospitalization. N Engl J Med 2004;351:1296-1305.

$\checkmark 2$ Culleton BF, Larson MG, Wilson PW, et al: Cardiovascular disease and mortality in a community-based cohort with mild renal insufficiency. Kidney Int 1999;56:2214-2219.

3 Goodkin DA, Bragg-Gresham JL, Koenig KG, et al: Association of comorbid conditions and mortality in hemodialysis patients in Europe, Japan, and the United States; the Dialysis Outcomes and Practice Patterns Study (DOPPS). J Am Soc Nephrol 2003; 14:3270-3277.

$\checkmark 4$ Foley RN: Cardiac disease in chronic uremia: can it explain the reverse epidemiology of hypertension and survival in dialysis patients? Semin Dial 2004; 17:275-278.

5 Barret BJ: Reducing the burden of cardiovascular disease in patients on dialysis. Dial Transplant 2002;31:155-163.

-6 Culleton BF, Hemmelgram B: Inadequate treatment of cardiovascular disease and cardiovascular disease risk factors in dialysis patients. Semin Dial 2004; 17:342-345.

$>7$ Port FK, Eknoyan G: The Dialysis Outcomes and Practice Patterns Study (DOPPS) and the Kidney Disease Outcomes Quality Initiative (K/DOQI): a cooperative initiative to improve outcomes for hemodialysis patients worldwide. Am J Kidney Dis 2004;44(suppl 3): $1-6$.

-8 Sarnak MJ, Coronado BE, Greene T, et al: Cardiovascular disease risk factors in chronic renal insufficiency. Clin Nephrol 2002;57:327-335.

$\checkmark 9$ McMahon LP: Hemodynamic cardiovascular risk factors in chronic kidney disease: what are the effects of intervention? Semin Dial 2003; 16:128-139.

10 Kalantar-Zadeh K, Block G, Humphreys MH, et al: Reverse epidemiology of cardiovascular risk factors in maintenance dialysis. Kidney Int 2003;63:793-808.

11 Busch M, Franke S, Müller A, et al: Potential cardiovascular risk factors in chronic kidney disease: AGEs, total homocysteine and metabolites, and the C-reactive protein. Kidney Int 2004;66:338-347.

12 Uhlig K, Levey AS, Sarnak MJ: Traditional cardiac risk factors in individuals with chronic kidney disease. Semin Dial 2003;16:118-127.

13 Zoccali C, Mallamaci F, Tripepi G: Traditional and emerging cardiovascular risk factors in end-stage renal disease. Kidney Int 2003; 63(suppl 85):S105-S110.
14 Levin A: Cardiac disease in chronic kidney disease: current understandings and opportunities for change. Blood Purif 2004;22:21-27.

$>15$ Sarnak MJ: Cardiovascular complications in chronic kidney disease. Am J Kidney Dis 2003; 41:S11-S17.

16 Krane V, Wanner C: Cardiovascular disease and predisposing factors in chronic renal failure. J Clin Basic Cardiol 2001;4:97-100.

17 Coresh J, Astor B, Sarnak MJ: Evidence for increased cardiovascular disease risk in patients with chronic kidney disease. Curr Opin Nephrol Hypertens 2004;13:73-81.

18 Ritz E: Atherosclerosis in dialyzed patients. Blood Purif 2004;22:28-37.

19 Stenvinkel P: Inflammation in end-stage renal disease - A fire that burns within. Contrib Nephrol 2005;149:185-199.

20 Zimmermann J, Herrlinger S, Pruy A, Metzger $\mathrm{T}$, Wanner C: Inflammation enhances cardiovascular risk and mortality in hemodialysis patients. Kidney Int 1999;55:648-658.

21 Bologa RM, Levine DM, Parker TS, Cheigh JS Serur D, Stenzel KH, Rubin AL: Interleukin-6 predicts hypoalbuminemia, hypocholesterolemia, and mortality in hemodialysis patients Am J Kidney Dis 1998;32:107-114

22 Interleukin-6 is a stronger predictor of total and cardiovascular mortality than C-reactive protein in haemodialysis patients. Nephrol Dial Transplant 2004; 19:1154-1160.

23 Wratten ML, Galaris D, Tetta C, Sevanian A: Evolution of oxidative stress and inflammation during hemodialysis and their contribution to cardiovascular disease. Antioxid Redox Signal 2003;4:935-944.

24 Kramer H, Toto R, Peshock R, Cooper R, Victor R: Association between chronic kidney disease and coronary artery calcification: the Dallas Heart Study. J Am Soc Nephrol 2004; 16 507-513.

25 Culleton BF, Larson MG, Wilson PWF, Evans JC, Parfrey PS, Levy D: Cardiovascular disease and mortality in a community-based cohort with mild renal insufficiency. Kidney Int 1999;56:2214-2219.

26 Jungers P, Massy ZA, Khoa TN, Labrunie M, Lacour B, Descamps-Latscha B, Man NK: Incidence and risk factors of atherosclerotic accidents in predialysis chronic renal failure patients: a prospective study. Nephrol Dial Transplant 1997;12:2597-2607.
27 Sarnak MJ, Levey AS: Cardiovascular disease and chronic renal disease: a new paradigm. Am J Kidney Dis 2000;35:S117-S131.

28 Harjai KJ: Potentially new cardiovascular risk factors: left ventricular hypertrophy, homocysteine, lipoprotein (a), triglycerides, oxidative stress, and fibrinogen. Ann Intern Med 1999; 131:376-386.

29 Stenvinkel P, Lindholm B, Heimburger M Heimburger O: Elevated serum levels of soluble adhesion molecules predict death in predialysis patients: association with malnutrition, inflammation, and cardiovascular disease. Nephrol Dial Transplant 2000;15:16241630.

30 Kaysen GA, Chertow GM, Adhikarla R, Young $\mathrm{B}$, Ronco $\mathrm{C}$, Levin N: Inflammation and dietary protein intake exert competing effects on serum albumin and creatinine in hemodialysis patients. Kidney Int 2001;60:333-340.

31 Bammens B, Evenepoel P, Verbeke K, et al: Protein-bound solutes: explaining the dissociation between urea reduction ratio and patient outcome? J Am Soc Nephrol 2003; 14:911.

32 Jolivot A, Combarnous F, Geleen G, et al: Leptin kinetics and clearance during maintenance hemodialysis: effect of high-flux membranes. Nephrol Dial Transplant 2003;18(suppl 4):M617.

-33 Wanner C, Bahner U, Mattern R, et al: Effect of dialysis flux and membrane material on dyslipidemia and inflammation in haemodialysis patients. Nephrol Dial Transplant 2004;19: 2570-2575.

34 Bowry SK: Dialysis membranes today. Int J Art Organs 2002;25:447-460.

35 Ronco C, Bowry S: Nanoscale modulation of the pore dimensions, size distribution and structure of a new polysulfone-based high-flux dialysis membrane. Int J Artif Organs 2001;24:

36 Ronco C, Bowry SK, Brendolan A, Crepaldi C, Soffiati G, Fortunato A, Bordoni V, Granziero A, Torsello G, La Greca G: Hemodialyzer: from macro-design to membrane nanostructure; the case of the FX-class of hemodialyzers. Kidney Int 2002;80(suppl):126-142.

37 Ayli D, Ayli M, Yuksei C, et al: The effect of high-flux hemodialysis on renal anemia. J Nephrol 2004; 17:701-706.

- 38 Cappelli G, Tetta C, Canaud B: Is biofilm a cause of silent chronic inflammation in haemodialysis patients? A fascinating working hypothesis. Nephrol Dial Transplant 2005;20: 266-270. 
39 Weber V, Linsberger I, Rossmanith E, et al: Pyrogen transfer across high- and low-flux hemodialysis membranes. Artif Organs 2004;28: 210-217.

-40 Schindler R, Christ-Kohlrausch F, Frei U, Shaldon S: Differences in the permeability of high-flux dialyzer membranes for bacterial pyrogens. Clin Nephrol 2003;59:447-454.

-41 Reznikov LL, Waksman J, Azam T, et al: Effect of advanced glycation end products on endotoxin-induced TNF-alpha, IL-1beta and IL-8 in human peripheral blood mononuclear cells. Clin Nephrol 2004;61:324-336.

42 Hsu PY, Lin CL, Yu CC, et al: Ultrapure dialysate improves iron utilization and erythropoietin response in chronic hemodialysis patients - A prospective cross-over study. J Nephrol 2004;17:693-700.

43 European Best Practice Guidelines for Haemodialysis (part 1): produced by the EBPG expert group on haemodialysis. Nephrol Dial Transplant 2002;17(suppl):7.

44 Bammens B, Evenepoel P, Verbeke K, et al: Removal of protein-bound solute $p$-cresol by convective transport: a randomized crossover study. Am J Kidney Dis 2004;44:278-285.

-45 Ahrenholz PG, Winkler RE, Bowry SK, et al: Dialysis membrane-dependent removal of middle molecules during hemodiafiltration: the $\beta_{2}$-microglobulin/albumin relationship. Clin Nephrol 2004;62:21-28.

46 Bonomini M, Ballone E, Di Stante S, et al: Removal of uraemic plasma factor(s) using different dialysis modalities reduces phosphatidylserine exposure in red blood cells. Nephrol Dial Transplant 2004; 19:68-74.
47 Locatelli F, Buoncristiani U, Canaud B, et al: Haemodialysis with on-line monitoring equipment: tools or toys? Nephrol Dial Transplant 2005;20:22-33.

48 Cheung AK, Levin NW, Greene T, Agodoa L, Bailey J, Beck G, Clark W, Levey AS, Leypoldt JK, Ornt DB, Rocco MV, Schulman G, Schwab S, Teehan B, Eknoyan G: Effects of high-flux hemodialysis on clinical outcomes: results of the HEMO study. J Am Soc Nephrol 2003; 14 3251-3263.

49 Di Fillipo S, Manzoni C, Andrulli S, et al: How to determine ionic dialysance for the online assessment of delivered dialysis dose. Kidney Int 2001;59:774-782.

50 Donauer J, Böhler J: Rationale for the use of blood volume and temperature control devices during hemodialysis. Kidney Blood Press Res 2003;26:82-89.

51 Boer W, Claus M, Cremaschi L, et al: Less intradialytic complications with blood volume control. Nephrol Dial Transplant 2002;17(suppl 1):127-128.

52 Maggiore Q, Pizzarelli F, Santoro A, et al: The effects of control of thermal balance on vascular stability in hemodialysis patients: results of the European randomized clinical trial. Am J Kidney Dis 2002;40:280-290.

53 Passlick-Deetjen J, Pohlmeier R: On-line hemodiafiltration. Gold standard or top therapy. Contrib Nephrol 2002;137:201-211.
54 Canaud B, Bragg-Gresham JL, Marshall MR, Desmeules S, Gillispie BW, Depner T, Klassen $\mathrm{P}$, Port FK: Patients receiving hemodiafiltration of hemofiltration have lower mortality risk than patients receiving hemodialysis without replacement fluid (HD) in Europe: The Dialysis Outcomes and Practice Patterns Study (DOPPS) (abstract). J Am Soc Nephrol 2003; 14:31A.

55 Steil H, Amato C, Carioni C, Kirchgessner J, Marcelli D, Mitteregger A, Moscardo V, Orlandini G, Gatti E: EuCliD - A medical registry. Methods Inf Med 2004;43:83-88.

56 Jirka T, Cesare S, Di Benedetto A, Perera Chang M, Ponce P, Richards N: The impact of on-line haemodiafiltration (HDF) on patient survival: results from a large network database. Nephrol Dial Transplant 2005;20:v18-v19.

57 Vaslaki LR, Berta K, Major L, Weber V, Weber C, Wojke R, Passlick-Deetjen J, Falkenhagen D: On-line hemodiafiltration does not induce inflammatory response in end-stage renal disease patients: results from a multicenter crossover study. Artif Organs 2005;29:406-412.

58 Pedrini LA, De Cristofaro VA: On-line mixed hemodiafiltration with a feedback for ultrafiltration control: effect on middle-molecule removal. Kidney Int 2003;4:1505-1513.

59 Man NK: Controversies and issues in hemodiafiltration therapy. Blood Purif 2004;22 (suppl 2):2-7.

60 www.anaes.f

61 Bowry SK, Kuchinke-Kiehn U, Ronco C: The cardiovascular burden of the dialysis patient: the impact of dialysis technology; in Ronco C, Brendolan A, Levin NW (eds): Cardiovascular Disorders in Hemodialysis. Contrib Nephrol. Basel, Karger, 2005, vol 149, pp 230-239. 